\title{
Wideband Pattern Reconfigurable Printed-Yagi Antenna Array Based on Feed Structure
}

\author{
Fukun Sun (1), Fushun Zhang (1), Chaoqiang Feng \\ National Key Laboratory of Antennas and Microwave Technology, Xidian University, Xi'an, P. R. China. \\ fksun12345@163.com,fshzhang@mail.xidian.edu.cn,Chaoqiang_feng@126.com
}

\begin{abstract}
A pattern reconfigurable antenna array with two elements is designed in this paper. The antenna element is made up of a printed Yagi and feed structure with variable phase. By changing the states of diodes in the feed structure of these two elements, the far-field radiation phase of both elements can be changed. That is, the pattern reconfigurable function of the array is realized. In this way, the impedance bandwidth of array is $75.9 \%$ $(2.7 \sim 6.0 \mathrm{GHz})$, in which the peak gain direction can be switched between $-\theta, 0$ and $+\theta\left(\theta=10^{\circ} \sim 16^{\circ}\right.$ at different frequencies $)$. With the simple reconfigurable structure, the peak gain direction can be adjusted according to demands. It can be applied to broadband investigation systems. To verify the feasibility, a prototype is fabricated, measured, and reasonable agreement between the simulated and measured results is obtained.
\end{abstract}

Index Terms - Pattern reconfigurable, antenna array, printed-Yagi, wideband.

\section{INTRODUCTION}

Recently, reconfigurable antennas are the focus of research because they have more flexibility than normal antennas under the same aperture. Thus, reconfigurable antennas can meet additional requirements of various modern wireless systems. Generally, reconfigurable antennas are classified as frequency [1], [2], polarization [3], [4] pattern [5]-[10], and hybrid reconfigurable antennas [11], [13]. In particular, reconfigurable patterns include three beam forms: broadside and conical switchable beams [5], [6], azimuth switchable beams [7], [8] and elevation switchable beams [9]-[11]. In this paper, antennas with elevation switchable beam are discussed.

In [9], the main beam of antenna can be switched to five directions by using the principle of the switchable director and reflector. However, its structure is so complex that it is not suitable for reconfigurable arrays. In [10], and [11], two patch antennas are also designed by the principle of switchable directors with simple structure, but the bandwidth of $5.6 \%$ and $1.7 \%$ is not appropriate for investigation systems. Therefore, pattern reconfigurable antenna arrays with wideband performance are needed.

In this paper, a two-element array is designed, the pattern of which can be changed by four groups of radio frequency (RF) switches on each element to achieve the reconfigurable pattern in elevation plane. The impedance bandwidth of the array is $75.9 \%$, and the peak gain direction can be switched among $-\theta, 0$ and $+\theta\left(\theta=10^{\circ} \sim 16^{\circ}\right.$ at different frequencies $)$. The remainder of this paper is organized as 
follows. The antenna configuration and detailed design are depicted in the 2 nd section. Then, a prototype is simulated, manufactured, and measured in the 3rd section. Finally, a conclusion is given in the last section.

\section{ANTENNA DESIGN AND CHARACTERISTICS}

It can be seen that the antenna array includes two reconfigurable antenna elements and a metal ground in Fig. 1. In order to facilitate the installation, the metal ground is trenched and fixed to the antenna element. The direct current (DC) bias circuit is printed on the upper surface of the ground, which is easy to be soldered with the DC bias circuit of the element. In addition, A and B are the soldering points of the external circuit. Each element has four groups of PIN diodes. The PIN diodes of the two elements are installed in opposite position to ensure the formation of different far-field radiation phases. The specific structural parameters of the antenna array are given in Table I.

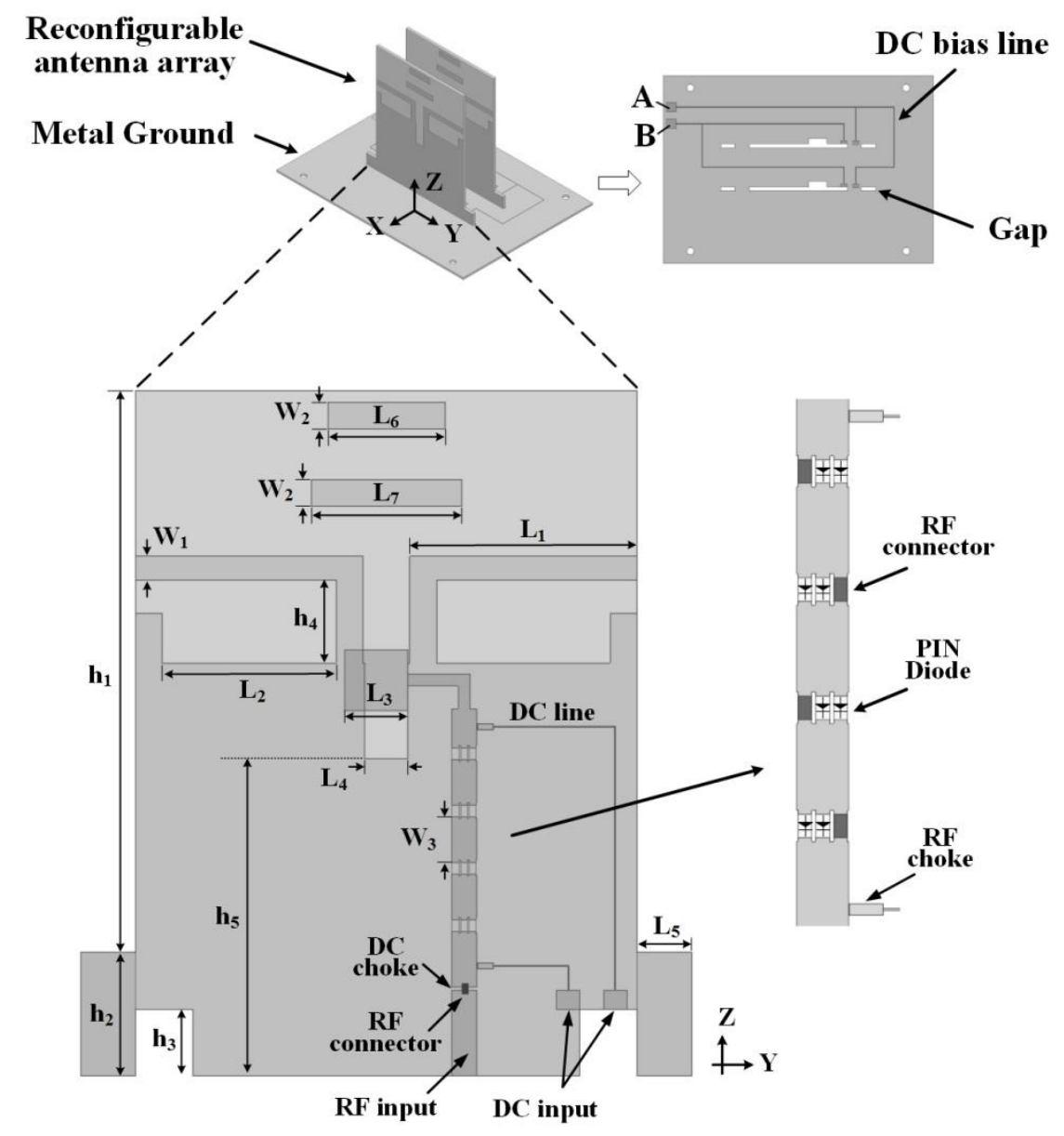

Fig. 1. Designs for the reconfigurable antenna.

The PIN diodes, RF connector and RF choke are labeled in the partial enlargement map, as shown in Fig. 1. A RF connector is connected in parallel with two RF switches to connect $50 \Omega$ transmission lines. They are called a group of switches. As shown in Fig. 2, when the switches are all turned on, it is equivalent to a common $50 \Omega$ transmission line. It can be noted that the arrangement of adjacent switches is different. Therefore, when the switches are all turned off, the current will take a detour in Brazilian Microwave and Optoelectronics Society-SBMO Received 27 Aug 2018; for review 31 Aug 2018; accepted 15 Apr 2019 
transmission process, that is, the physical length of the path is maximized. In this way, the phase of each element is different and the pattern can be reconstructed. What's more, the radiation pattern can also be adjusted to meet the requirements of larger angle migration by enlarging the number of PIN diodes.

Moreover, the specific RF switch voltage control is given in Table I to describe the working modes of Case 1, Case 2 and Case 3.
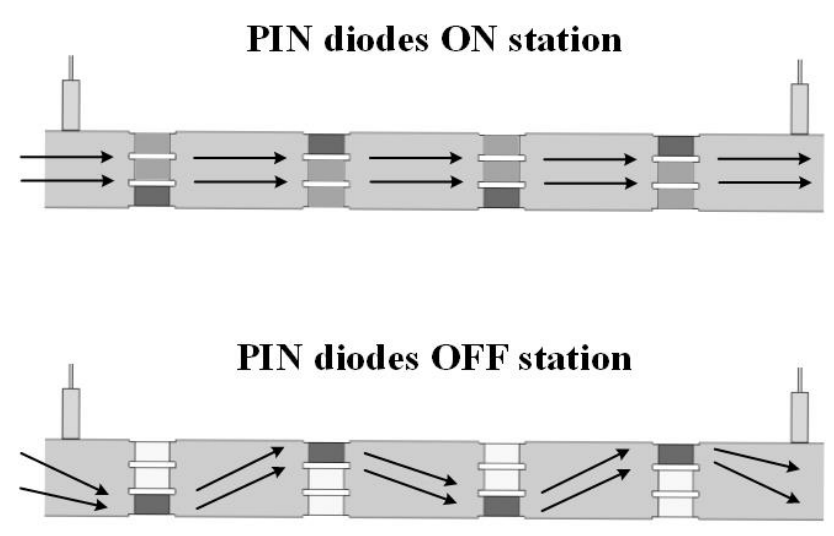

Fig. 2. The schematic diagram of current on the ON/OFF station of PIN diodes.

In order to better explain the working mode, the parameters of the antenna are analyzed by ANSYS HFSS software. In Fig. 3, the two curves of antenna element relative phase of far-field radiation with ON station and OFF station are given at different frequencies. It can be seen that the phase change tends to increase with the increase of frequency within limits of 2.5 6.0 GHz. And the phase change at $6.0 \mathrm{GHz}$ is the maximum of $\Delta \varphi \approx 36.9^{\circ}$ ( $\varphi$ means the far -field radiation phase of antenna element). So two elements can be designed to get a phase diversity by changing the ON station or OFF station, which can forms a patterns selectivity array.

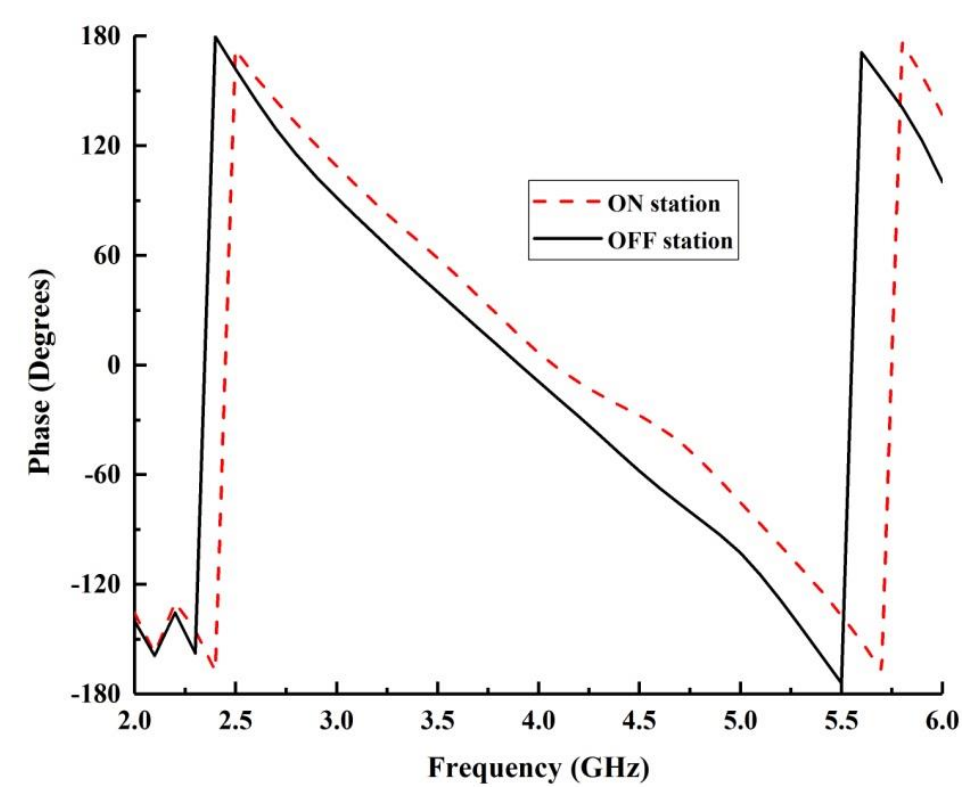

Fig. 3. The antenna element relative phase of far-field radiation with ON station and OFF station at different frequencies. 

DOI: http://dx.doi.org/10.1590/2179-10742019v18i21442

TABLE I. ANTENNA DIMENSIONS

\begin{tabular}{cccc}
\hline \hline Parameter & Value $(\mathrm{mm})$ & Parameter & Value $(\mathrm{mm})$ \\
\hline $\mathrm{L}_{1}$ & 23.8 & $\mathrm{~W}_{2}$ & 2.8 \\
\hline $\mathrm{L}_{2}$ & 18.2 & $\mathrm{~W}_{3}$ & 4.4 \\
\hline $\mathrm{L}_{3}$ & 6.7 & $\mathrm{~h}_{1}$ & 58.8 \\
\hline $\mathrm{L}_{4}$ & 4.6 & $\mathrm{~h}_{2}$ & 13.0 \\
\hline $\mathrm{L}_{5}$ & 5.8 & $\mathrm{~h}_{3}$ & 7.0 \\
\hline $\mathrm{L}_{6}$ & 12.3 & $\mathrm{~h}_{4}$ & 8.8 \\
\hline $\mathrm{L}_{7}$ & 15.8 & $\mathrm{~h}_{5}$ & 33.3 \\
\hline $\mathrm{W}_{1}$ & 2.5 & & \\
\hline
\end{tabular}

TABLE II. CONFIGURATIONS OF THE A AND B PORTS TO ACHIEVE RECONFIGURABLE ANTENNA

\begin{tabular}{|c|c|c|c|}
\hline Mode & A Port & B Port & Peak Gain Direction \\
\hline Case 1 & $0 \mathrm{~V}$ & $0 \mathrm{~V}$ & $0^{\circ}$ \\
\hline Case 2 & $4 \mathrm{~V}$ & $0 \mathrm{~V}$ & $-\theta\left(\theta=10^{\circ} \sim 16^{\circ}\right)$ \\
\hline Case 3 & $0 \mathrm{~V}$ & $4 \mathrm{~V}$ & $+\theta\left(\theta=10^{\circ} \sim 16^{\circ}\right)$ \\
\hline
\end{tabular}

\section{EXPERIMENTAL RESULTS AND COMPARISON}

Simulations were performed using ANSYS HFSS. To validate the design, a prototype of the proposed antenna array is simulated, fabricated and tested. The structures of the array are fabricated on FR4 substrates, with a dielectric constant of 4.4 and a loss tangent of 0.02 . The reflection coefficients were measured using the Wiltron 37269A Network Analyzer and the radiation patterns were measured by the time-gating method. The comparison method is used to measure the realized gain. Then, the simulation and test results of VSWRs and Gain are all given in Fig. 4. The Fig. 5 shows the directional patterns including the co-polarized and cross-polarized patterns at $2.8 \mathrm{GHz}, 4.4 \mathrm{GHz}$ and $5.8 \mathrm{GHz}$. Photos of prototype are shown in Fig. 6.

The selected components for the prototype were: PIN diodes (SMP1345-079LF) for switches; Inductors $(220 \mathrm{nH})$ adopted in the DC-biasing circuits for RF chokers; Capacitors (22 uF) act as RF connectors.

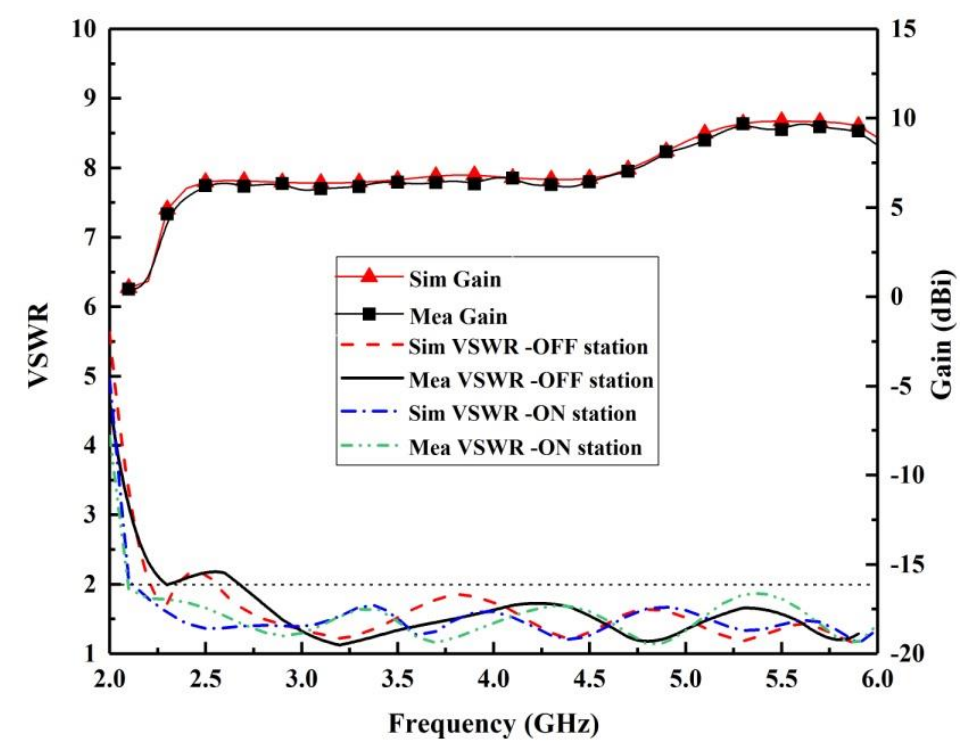

Fig. 4. Measured and simulated VSWRs and Gains of the proposed antenna. 
Journal of Microwaves, Optoelectronics and Electromagnetic Applications, Vol. 18, No. 2, June 2019 DOI: http://dx.doi.org/10.1590/2179-10742019v18i21442
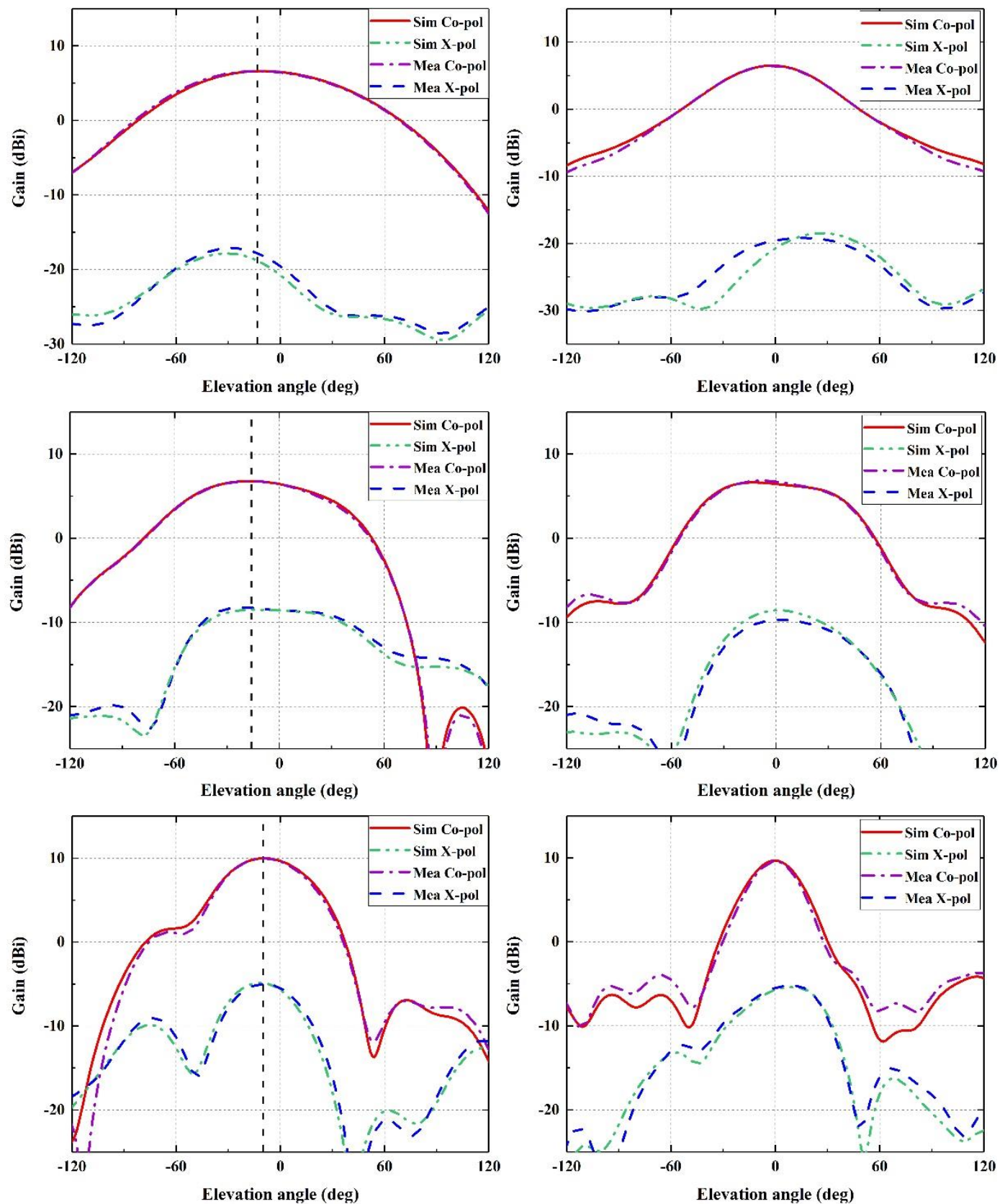

Fig. 5. Measured and simulated radiation patterns of (a) H-plane (b) E-plane at 2.8 GHz and (c) H-plane (d) E-plane at 4.4 $\mathrm{GHz}$ and (e) H-plane (f) E-plane at $5.8 \mathrm{GHz}$
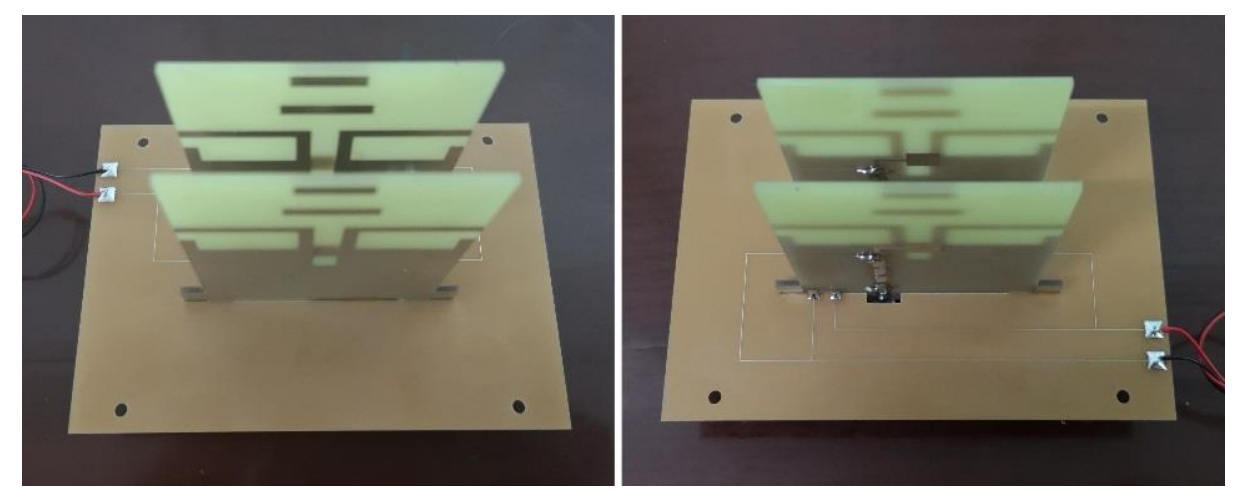

Fig. 6. Fabricated reconfigurable antenna array.

Brazilian Microwave and Optoelectronics Society-SBMO Brazilian Society of Electromagnetism-SBMag
Received 27 Aug 2018; for review 31 Aug 2018; accepted 15 Apr 2019 (C) 2019 SBMO/SBMag (cc) BY 
In Fig. 4, it is known that the simulation and test results of VSWRs and Gain coincide. The impedance bandwidth is $75.9 \%(2.7 \sim 6.0 \mathrm{GHz})$, and the stability Gain is more than $6.0 \mathrm{dBi}$. In Fig. 5, the simulation of the pattern is also consistent with the test results. At begin of the band, the radiation direction of pattern is at $\theta=-13^{\circ}$, and the gain is $6.6 \mathrm{dBi}$ with the $24.4 \mathrm{~dB}$ of the cross polarization. At center of the band, the radiation direction of pattern is at $\theta=-16^{\circ}$, and the gain is $6.8 \mathrm{dBi}$ with the $15.3 \mathrm{~dB}$ of the cross polarization. At end of the band, the radiation direction of the pattern is at $\theta=-$ $10^{\circ}$, and the gain is $10.0 \mathrm{dBi}$ with the $15.0 \mathrm{~dB}$ of the cross polarization. Therefore, in this paper, the test performance of array achieves the requirement of reconfigurable performance.

\section{CONCLUSION}

In this paper, a pattern reconfigurable antenna array with two elements is designed. The impedance bandwidth is $75.9 \%(2.7 \sim 6.0 \mathrm{GHz})$, and the stability Gain is more than $6.0 \mathrm{dBi}$. The radiation direction can be adjusted on the H-plane to achieve a switching among $-\theta, 0$ and $+\theta\left(\theta=10^{\circ} \sim 16^{\circ}\right.$ at different frequencies). The measured antenna is consistent with the simulation results and can be applied to the reconnaissance system. Because of the simple reconfigurable structure, the radiation pattern will be adjusted to meet the requirements of larger angle migration.

\section{REFERENCES}

[1] H. A. Majid, M. K. Abd Rahim, M. R. Hamid, and M. F. Ismail, "Frequency reconfigurable microstrip patch-slot antenna with directional radiation pattern," Progress In Electromagnetics Research, vol. 144, pp. 319-328, 2014.

[2] F. Zadehparizi and S. Jam, "Increasing reliability of frequency- reconfigurable antennas," IEEE Antennas and Wireless Propagation Letters, vol. 17, no. 5, pp. 920-923, May. 2018.

[3] W.-B. Wei, Q.-Z. Liu, Y.-Z. Yin, and H.-J. Zhou, "Reconfigurable microstrip patch antenna with switchable polarization,” Progress In Electromagnetics Research, vol. 75, pp. 63-68, 2007.

[4] J. S. Row and Y. H. Wei, "Wideband reconfigurable crossed-dipole antenna with quad-polarization diversity," IEEE Transactions on Antennas and Propagation, vol. 66, no. 4, pp. 2090-2094, Apr. 2018.

[5] W. Lin, H. Wong and R. W. Ziolkowski, "Wideband pattern-recon- figurable antenna with switchable broadside and conical beams," IEEE Antennas and Wireless Propagation Letters, vol. 16, pp. 2638-2641, 2017.

[6] P. Y. Qin, Y. J. Guo, A. R. Weily and C. H. Liang, "A pattern reconfigurable U-slot antenna and its applications in MIMO systems," IEEE Transactions on Antennas and Propagation, vol. 60, no. 2, pp. 516-528, Feb. 2012.

[7] M. S. Alam and A. Abbosh, "Planar pattern reconfigurable antenna with eight switchable beams for WiMax and WLAN applications," IET Microwaves, Antennas \& Propagation, vol. 10, no. 10, pp. 1030-1035, Jul. 2016.

[8] Y. Yang, R. B. V. B. Simorangkir, X. Zhu, K. Esselle and Q. Xue, "A novel boresight and conical pattern reconfigurable antenna with the diversity of $360^{\circ}$ polarization scanning," IEEE Transactions on Antennas and Propagation, vol. 65, no. 11, pp. 5747-5756, Nov. 2017.

[9] S. L. Chen, P. Y. Qin, W. Lin and Y. J. Guo, "Pattern-reconfigurable antenna with five switchable beams in elevation plane," IEEE Antennas and Wireless Propagation Letters, vol. 17, no. 3, pp. 454-457, Mar. 2018.

[10] W. Q. Deng, X. S. Yang, C. S. Shen, J. Zhao and B. Z. Wang, "A dual-polarized pattern reconfigurable yagi patch antenna for microbase stations," IEEE Transactions on Antennas and Propagation, v. 65, no. 10, pp. 5095-5102, Oct. 2017.

[11] M. Jusoh, T. Sabapathy, M. F. Jamlos and M. R. Kamarudin, "Reconfigurable four-parasitic-elements patch antenna for high-gain beam switching application," IEEE Antennas and Wireless Propagation Letters, vol. 13, pp. 79-82, 2014.

[12] Y. P. Selvam et al., "A low-profile frequency- and pattern-reconfigurable antenna," IEEE Antennas and Wireless Propagation Letters, vol. 16, pp. 3047-3050, 2017.

[13] N. Nguyen-Trong, L. Hall and C. Fumeaux, "A frequency- and pattern-reconfigurable center-shorted microstrip antenna," IEEE Antennas and Wireless Propagation Letters, vol. 15, pp.1955-1958, 2016. 